\title{
Primary Prevention of Asthma: Age and Sex Influence Sensitivity to Allergen-Induced Airway Inflammation and Contribute to Asthma Heterogeneity in Guinea Pigs
}

\author{
Jean F. Regal ${ }^{a} \quad$ Ronald R. Regal $^{b} \quad$ Jessica L. Meehan ${ }^{a} \quad$ Margaret E. Mohrman $^{a}$ \\ ${ }^{a}$ Department of Biochemistry and Molecular Biology, Medical School Duluth, and ${ }^{\mathrm{b}}$ Department of \\ Mathematics and Statistics, College of Science and Engineering, University of Minnesota, Duluth, Minn., USA
}

\section{Key Words}

Eosinophil · Guinea pig model of asthma - Airway

inflammation - Ovalbumin

\begin{abstract}
Background: Limiting allergen exposure in the sensitization phase has been proposed as a means of primary prevention of asthma, but its effectiveness is debated. Hypothesis: Primary prevention of asthma is more effective in limiting asthma symptoms in young guinea pigs compared with adults, whether males or females. Methods: The following experimental groups were used: young/young, sensitized and challenged before sexual maturity; young/adult, sensitized young and challenged after sexual maturity; adult/adult, sensitized and challenged after sexual maturity. Males and females were sensitized intraperitoneally with varying doses of ovalbumin (OVA) and challenged intratracheally with a constant OVA dose. Cellular infiltration into lung and lavage fluid as well as airway hyperresponsiveness to intravenous methacholine was determined 24 h later. Results: In unsensitized animals, density of resident inflammatory cells as well as baseline pulmonary function differed with age and sex. Maximum OVA-induced eosinophilia in females occurred at a lower sensitizing dose of OVA than in males, and the slopes of the dose-response relationship differed significantly be-
\end{abstract}

tween sexes. Young females had more pronounced increases in eosinophils compared with some adult treatment groups. The concentrations of OVA-specific antibodies were not directly related to differences in cellular infiltration. Airway hyperresponsiveness to methacholine challenge was observed in all treatment groups. Conclusion: Young animals require major reductions in allergen exposure compared with adults to effectively limit airway inflammation in primary prevention. Heterogeneity of asthma symptoms seen with age and sex suggests that primary prevention by limiting allergen exposure or treatment with anti-inflammatory or bronchodilator drugs may be more effective strategies for specific age and gender populations.

Copyright $\odot 2006$ S. Karger AG, Basel

\section{Introduction}

Limiting allergen exposure has been proposed as a strategy to control asthma, either by preventing sensitization (primary prevention) or by preventing symptoms once sensitization has occurred (secondary prevention) [1]. Currently, there are no generally accepted criteria for threshold levels of allergens inducing sensitization or eliciting the asthmatic symptoms. However, there is evidence in humans that a correlation exists between ex-

\section{KARGER}

Fax +4161306 1234 E-Mail karger@karger.ch www.karger.com (c) 2006 S. Karger AG, Basel

$1018-2438 / 06 / 1413-0241 \$ 23.50 / 0$

Accessible online at:

www.karger.com/iaa
Correspondence to: Jean F. Regal, PhD

Department of Biochemistry and Molecular Biology

Medical School Duluth, University of Minnesota, 1035 University Dr.

Duluth, MN 55812 (USA)

Tel. +1 218726 8950, Fax +1 218726 7906, E-Mail jregal@d.umn.edu 
posure levels and sensitization, as well as a correlation between exposure levels and severity of asthma [2]. Considering human exposures to dust mites, combined concentrations of the mite antigens Der $\mathrm{f} 1$ and Der $\mathrm{p} 1$ of $2 \mu \mathrm{g} / \mathrm{g}$ dust and $10 \mu \mathrm{g} / \mathrm{g}$ dust have been proposed as thresholds for sensitization and development of asthma, respectively [3]. Theoretically, primary prevention could be accomplished by limiting allergen exposure and preventing sensitization. Recent studies in adults have evaluated the effectiveness of reducing dust mite exposure by encasement of mattresses, but this single intervention was of limited usefulness in controlling asthma symptoms [4]. For occupational asthma in adults, avoiding sensitizing agents in the workplace is recommended and has been shown to be beneficial in various occupational settings including those involving latex allergy $[5,6]$. On the other hand, multifaceted primary prevention studies in children have shown some success [7]. This potential benefit in children may be due to the multifaceted approach that targeted multiple asthma triggers and/or the higher incidence of allergic asthma in children compared with adults. Estimates suggest that allergic asthma is responsible for $80 \%$ of asthma in children, whereas with adults, the estimates are $30-50 \%$ [2]. In general, recent reviews and recommendations regarding primary prevention of asthma conclude that multifaceted interventions to reduce allergen exposure may be of benefit in children, but additional research is needed before specific public health recommendations can be made for either children or adults $[1,8,9]$.

In childhood, the prevalence and mortality of asthma is highest in males. However, during adolescence, the prevalence of asthma is higher in females, and after age 25 , females have a higher death rate due to asthma $[2,10]$. Sex differences in asthma have also been noted in animal models. Certainly, sex steroids can modulate the immune system in general. More recent studies in a mouse asthma model indicated that antigen challenge resulted in less airway inflammation in male versus female mice, possibly due to a testosterone-induced decrease in Th2 cell responses [11]. In addition, female mice had greater increases in serum IgE [12]. These studies examined a single sensitizing dose of allergen in adult animals only.

The purpose of the present study was to systematically determine if limiting allergen exposure in the sensitization phase (primary prevention) would be a more effective strategy of asthma control in certain age or sex groups. We hypothesized that primary prevention would be more effective in limiting asthma symptoms in young animals compared with adults, whether males or females.
In limiting allergen exposure, differences in the magnitudes or in the dose-related patterns of asthma symptoms depending on age or sex would provide evidence that primary prevention strategies are more effective for particular age and sex groups. A guinea pig model of asthma was chosen because our previous studies using the occupational allergen trimellitic anhydride had demonstrated that both young and adult animals accumulated eosinophils in response to allergen, but the magnitude of the eosinophilia varied with age [13]. In addition, with antigen as the stimulus in passively sensitized male guinea pigs, Arakawa et al. [14] found that antigen-induced bronchoconstriction and plasma exudation occurred at lower challenge doses in mature (13 weeks) compared with immature guinea pigs ( 2 weeks). However, the maximal bronchoconstrictor response to ovalbumin (OVA) and the effectiveness of an antihistamine were greater in immature animals compared with mature animals. Neither of these studies evaluated the effect of limiting allergen exposure during the sensitization phase.

Symptoms of asthma can include varying degrees of reversible airflow obstruction, mucus secretion, airway hyperresponsiveness and cellular infiltration into the lung, particularly eosinophilia [15]. In our present study with guinea pigs, the sensitizing dose of allergen was varied, using young and adult animals, males and females, to determine whether interventions to reduce allergen load might be more beneficial in the primary prevention of adult onset asthma, childhood asthma, or asthma persistence into adulthood. Cellular infiltration into the lung and airway hyperresponsiveness were the asthma endpoints assessed. These studies also investigated the contributions of age and sex to the heterogeneity of asthma to determine if treatment of asthma should target inflammation or airway constriction preferentially in specific age and gender groups.

\section{Materials and Methods}

\section{Experimental Design}

All animal experiments were carried out in accordance with the Guide for the Care and Use of Laboratory Animals as adopted and promulgated by the US National Institutes of Health. Hartley guinea pigs were purchased from Charles River Laboratories, Kingston, New York facility. All animals were weaned by Charles River and shipped to Duluth, Minn., on postnatal day 7. According to data from Charles River Laboratories [16], sexual maturity in outbred Hartley male guinea pigs occurs in the range of 56-70 days after birth, after which we refer to an animal as an adult. In female guinea pigs, sexual maturity is achieved from 35 to 42 days after birth. To ensure that sexual maturity was reached, adult an- 
Table 1. Experimental groups of guinea pigs for cellular infiltration and airway hyperresponsiveness

\begin{tabular}{|c|c|c|c|c|c|c|}
\hline \multirow[t]{2}{*}{ Group } & \multirow[t]{2}{*}{$\mathrm{n}$} & \multicolumn{2}{|c|}{ Sensitization } & \multicolumn{2}{|l|}{ Challenge } & \multirow{2}{*}{$\begin{array}{l}\text { Sensitization/ } \\
\text { challenge interval } \\
\text { days }\end{array}$} \\
\hline & & age, days & body weight, g & age, days & body weight, g & \\
\hline \multicolumn{7}{|l|}{$\mathrm{Y} / \mathrm{Y}$} \\
\hline Females & 52 & $9-11$ & $150.9 \pm 3.0$ & $29-31$ & $321.1 \pm 4.3$ & $20-21$ \\
\hline Males & 61 & $9-11$ & $153.3 \pm 3.5$ & $29-31$ & $339.5 \pm 6.1$ & $20-21$ \\
\hline \multicolumn{7}{|l|}{ Y/A } \\
\hline Females & 34 & $9-11$ & $148.7 \pm 4.4$ & $77-78$ & $595.9 \pm 12.8$ & $66-69$ \\
\hline Males & 33 & $9-11$ & $145.1 \pm 4.0$ & $105-108$ & $870.5 \pm 12.3$ & $95-99$ \\
\hline \multicolumn{7}{|l|}{$\mathrm{A} / \mathrm{A}$} \\
\hline Females & 53 & $56-58$ & $506.0 \pm 7.7$ & $77-80$ & $626.0 \pm 8.4$ & $21-22$ \\
\hline Males & 53 & $84-85$ & $767.5 \pm 10.9$ & $105-108$ & $869.5 \pm 10.5$ & $21-24$ \\
\hline
\end{tabular}

imals were used 2 weeks after the age range at which sexual maturity reportedly occurs. Three major treatment groups were considered as outlined in table 1: young/young (Y/Y), animals sensitized and challenged before sexual maturity; young/adult (Y/A), animals sensitized when young and challenged after sexual maturity; adult/adult (A/A), animals sensitized and challenged after sexual maturity. Animals were sensitized intraperitoneally with either saline (unsensitized animals) or varying doses of OVA in saline $(0.005,0.05,0.5,5$ and $50 \mathrm{mg} / \mathrm{kg})$. Intratracheal challenge of all animals used a single dose of OVA $(0.4 \mathrm{mg} / \mathrm{kg})$ and occurred 20-24 days ( $\mathrm{Y} / \mathrm{Y}$ and $\mathrm{A} / \mathrm{A}$ ), 66-69 days (female $\mathrm{Y} / \mathrm{A}$ ) or 95-99 days (male Y/A) after sensitization. At the beginning of the study, OVA was obtained from Sigma Chemical Co., St. Louis, Mo., USA (Grade V, A5503) and stock OVA solutions for both sensitization and challenge were made by serially diluting a $50 \mathrm{mg} / \mathrm{kg}$ solution. Aliquots of each solution were frozen and used for the full duration of the investigation. All OVA solutions were made in endotoxin-free saline or water. Concentrations of endotoxin were $160 \mathrm{EU} / \mathrm{mg}$ OVA (16 ng endotoxin/mg OVA) as determined by the Quantitative Chromogenic LAL assay (BioWhittaker, Walkersville, Md., USA). Littermates were tracked, and sensitization doses were varied across litters and over the time frame of the study. Because antigen challenge can cause severe bronchoconstriction and high mortality in guinea pigs, $30 \mathrm{~min}$ prior to intratracheal challenge with OVA, animals were injected intraperitoneally with $6.1 \mathrm{mg} / \mathrm{kg}$ of the $\mathrm{H} 1$ antagonist pyrilamine. Guinea pigs were then anesthetized with a combination of ketamine $(35 \mathrm{mg} / \mathrm{kg}$ i.m.) and xylazine ( $1 \mathrm{mg} / \mathrm{kg}$ i.m.) immediately prior to intratracheal challenge with $0.4 \mathrm{mg} / \mathrm{kg}$ OVA in a volume of $80 \mu \mathrm{l} / \mathrm{kg}$.

The present study reports results using 224 guinea pigs for cellular infiltration and a separate group of 62 animals for airway hyperresponsiveness to methacholine. An additional 15 guinea pigs died at the time of intratracheal challenge even with antihistamine pretreatment. Thus, data were not obtained for these 15 animals. The animals that died represented 6 male and 9 female animals sensitized anywhere from 0.005 to $50 \mathrm{mg} / \mathrm{kg}$, scattered amongst the 6 treatment groups with no definite pattern.

\section{Cellular Infiltration into the Lung}

Cellular infiltration in response to OVA challenge was evaluated 23-25 h after antigen challenge as previously described [17]. Both the airspace - cells in the bronchoalveolar lavage fluid (BAL) - and the tissue compartment were evaluated for cellular infiltration. As seen in table 1, the average weight range of our animals was large (280-870 g). To ensure that we were achieving similar sampling in the different age groups, we chose a lavage volume for each animal based on milliliters/kilogram. An adequate tidal volume employed for guinea pigs is $10 \mathrm{ml} / \mathrm{kg}$, so animals were lavaged with 4 washes of 1.5 times the tidal volume to wash the majority of the cells from the airspace. Four equal volumes of room temperature PBS, with a total lavage volume of $60 \mathrm{ml} / \mathrm{kg}$ body weight, were used. Lavage volume recovery was $88.7 \pm 0.4 \%$ for animals lavaged when young $(\mathrm{Y} / \mathrm{Y})$ and $93.6 \pm$ $0.2 \%$ for animals lavaged when adult (Y/A, A/A). Lavage volume recovery did not differ between male and female animals of the same age group. The BAL was centrifuged to sediment the cells, and the BAL cell pellet was resuspended in $1.0 \mathrm{ml}$ PBS. Total white blood cells in BAL were counted by standard methods in a hemacytometer. Differential counts were obtained from cytospin preparations of BAL cells $\left(3 \times 10^{4}\right.$ cells $)$ stained with a modified Wrights' stain (Diff Quik, American Scientific Products, McGraw Park, Ill., USA). Four hundred cells were counted and identified as eosinophils, neutrophils, lymphocytes or macrophages. The BAL cell differential and white blood cell counts were used to calculate the total number of each cell type recovered per animal from the BAL. For estimates of the numbers of eosinophils and neutrophils in the lung tissue, the left lung lobe was processed for measurement of eosinophil peroxidase (EPO) and the right lung lobe for myeloperoxidase (MPO) activity, respectively [17]. The remainder of the lung was dried at $80^{\circ} \mathrm{C}$ for $3-5$ days for determination of gram dry weight.

For an estimate of the total eosinophils in the lung tissue, EPO activity from the homogenized lung after lavage was expressed as total optical density/minute from the left caudal lobe. For an estimate of total neutrophils in the lung tissue, MPO activity from the homogenized lung after lavage was expressed as total units of 
enzyme activity from the right caudal lobe. Since the sizes of animals in this study ranged from approximately 100 to $1,000 \mathrm{~g}$, all EPO and MPO values were normalized using the gram dry weight of the lung obtained from that animal to approximate the density of a particular cell type in the lung of each animal. This was the important variable for comparison rather than simply comparing the total number of cells in a small lung compared with a large lung. Protein in the BAL supernatant was determined by the method of Lowry et al. [18], and the number of red blood cells (RBC) in the BAL was quantified by determining the optical density at $412 \mathrm{~nm}$ of the solution after lysis of the RBC as previously described [17]. No EPO enzyme activity was detectable in the BAL supernatant.

\section{Statistical Analysis of Cell Infiltration Data}

All data were log transformed to equalize variances and allow normal parametric modeling. Figures show the geometric mean +1 SE. Statistical significance was defined as $\mathrm{p}<0.05$. Statistical analyses used ANOVA or ANCOVA/linear regression with JMP and SAS software (SAS Institute Inc., Cary, N.C., USA). For differential cell counts, if no cells of the cell type of concern were seen in the 400 cells counted, the value used for statistical analysis was half of 1 cell or $0.125 \%$. This was necessary because of the log transformation of the data. As tested by ANOVA, litter effects were not significant. Because of the shape and character of the dose response and the variability of the data, statistical analyses examined three different aspects of the dose-response relationships for the variables depicted in figures 1-3. Each analysis considered the 6 different treatment groups (males or females and $\mathrm{Y} / \mathrm{Y}, \mathrm{Y} / \mathrm{A}, \mathrm{A} / \mathrm{A})$. The first analysis compared the starting values, or the magnitude of the variables in unsensitized animals (saline). To determine if resident cell populations differed with age and sex in unsensitized animals (saline), ANOVA was used to examine the effects of sex (males or females), challenge age (young or adult), and sex by challenge age interaction. For the second analysis, change in the variable from that noted in unsensitized animals to animals sensitized with $0.05 \mathrm{mg} / \mathrm{kg}$ OVA was evaluated by ANOVA to compare the initial rise in the dose-response relationship amongst the 6 different treatment groups. This initial rise from saline to $0.05 \mathrm{mg} / \mathrm{kg}$ was then compared amongst treatment groups. When such changes in the variables are statistically analyzed in the log scale, the analysis actually compares the ratio of the treated with the saline value, or the fold change in that value from the saline control. Finally, linear regression analysis was used to compare the slopes of the lines determined by the last 4 doses, $0.05-50 \mathrm{mg} / \mathrm{kg}$ OVA for sensitization. For the last 4 doses, ANCOVA tested for significance of sex, treatment (Y/Y, Y/A, $\mathrm{A} / \mathrm{A}$ ), dose and interactions for each of the variables. Table 2 summarizes the results of the statistical analysis of the data shown in figures 1-3.

\section{Measurement of Airway Hyperresponsiveness}

Airway hyperresponsiveness to intravenous methacholine was measured 23-25 h after intratracheal challenge with $0.4 \mathrm{mg} /$ $\mathrm{kg}$ OVA in male and female, Y/Y and A/A guinea pigs sensitized 20-24 days earlier with saline or $0.5 \mathrm{mg} / \mathrm{kg}$ OVA intraperitoneally. Guinea pigs were anesthetized with ketamine/xylazine. The trachea was cannulated, and the animal ventilated at 70 breaths per $\mathrm{min}, 10 \mathrm{ml} / \mathrm{kg}$ room air, using a computer-controlled piston ventilator (FlexiVent, SciReq, Montreal, Canada) and a water trap to maintain a positive end-expiratory pressure of $2-2.5 \mathrm{~cm}$ water. Baseline resistance and compliance were determined using a Snapshot 60 maneuver (SciReq FlexiVent 5.0 software) applying a sinusoidal signal at a frequency of $1 \mathrm{~Hz}$ for $1 \mathrm{~s}$ with a linear single compartment model to assess respiratory mechanics. Measurements were taken immediately before methacholine injection and every $20 \mathrm{~s}$ for $1 \mathrm{~min}$ following each dose of methacholine. Methacholine doses were diluted in PBS containing heparin and delivered by bolus injection into a dorsal branch of the saphenous vein of the hindfoot. Methacholine doses of 0.001, 0.0033, 0.01, 0.033 and $0.1 \mathrm{mg} / \mathrm{kg}$ were given at approximately $5 \mathrm{~min}$ intervals. Data were fitted using a single compartment model (FlexiVent 5.0 software) to obtain resistance and compliance. To standardize volume history, each baseline measurement was preceded by two consecutive inflations of the lung to total lung capacity, defined as a tracheal pressure of $30 \mathrm{~cm}$ water. A coefficient of determination for the single compartment model of 0.85 was used as the cutoff for a reasonable model fit. Due to extreme reactivity of the guinea pig airways at higher doses of methacholine, the model fit was unacceptable in a significant proportion of OVA-sensitized animals at methacholine doses greater than $0.0033 \mathrm{mg} / \mathrm{kg}$, so only data for 0.001 and $0.0033 \mathrm{mg} / \mathrm{kg}$ are shown.

\section{Statistical Analysis of Airway Hyperresponsiveness Data}

All data were log transformed to equalize variances and allow normal parametric modeling. ANOVA models were used to examine the effects of sex (males or females) and age (Y/Y or A/A) on baseline resistance and compliance in unsensitized (saline) animals. Individual contrasts compared each of the 4 treatment groups (fig. 5). ANOVA models were used to determine if OVA sensitization and challenge significantly changed baseline resistance or compliance. Individual contrasts were also conducted to determine if the OVA effect was significantly different in vehicletreated animals between each of the 4 treatment groups (** in fig. 6). To determine if OVA sensitization and challenge resulted in airway hyperresponsiveness in each of the 4 treatment groups (* in fig. 6), a repeated measures ANOVA used the following 2 repeated measures: (1) the ratio of the maximum change in the variable after $0.001 \mathrm{mg} / \mathrm{kg}$ methacholine to the vehicle value and (2) the ratio of the maximum change in the variable after $0.0033 \mathrm{mg} / \mathrm{kg}$ methacholine to the vehicle value. Individual contrasts comparing the magnitudes of the OVA effect were also conducted amongst the 4 treatment groups.

Determination of OVA-Specific IgG1 and Statistical Analysis

OVA-specific guinea pig IgG1 in serum was measured by ELISA as previously described for the antigen trimellitic anhydride, except ELISA plates in the current study were coated with $2 \mu \mathrm{g} / \mathrm{ml}$ OVA $[19,20]$. Concentrations of OVA-specific IgG1 in the unknown serum samples were expressed in terms of relative concentrations compared with that of a reference antibody which is defined as 1 .

OVA-specific IgG1 data (fig. 4) were analyzed by ANOVA for the sensitizing doses of $0.005-50 \mathrm{mg} / \mathrm{kg}$ OVA. A value of $1 \times$ $10^{-6}$ was assigned to animals with antibody levels below the limit of detection of the assay. For statistical analysis of OVA-specific IgG1 data, ANOVA was used to examine the effects of dose, sex, treatment group (Y/Y, Y/A, A/A) and their interactions. 


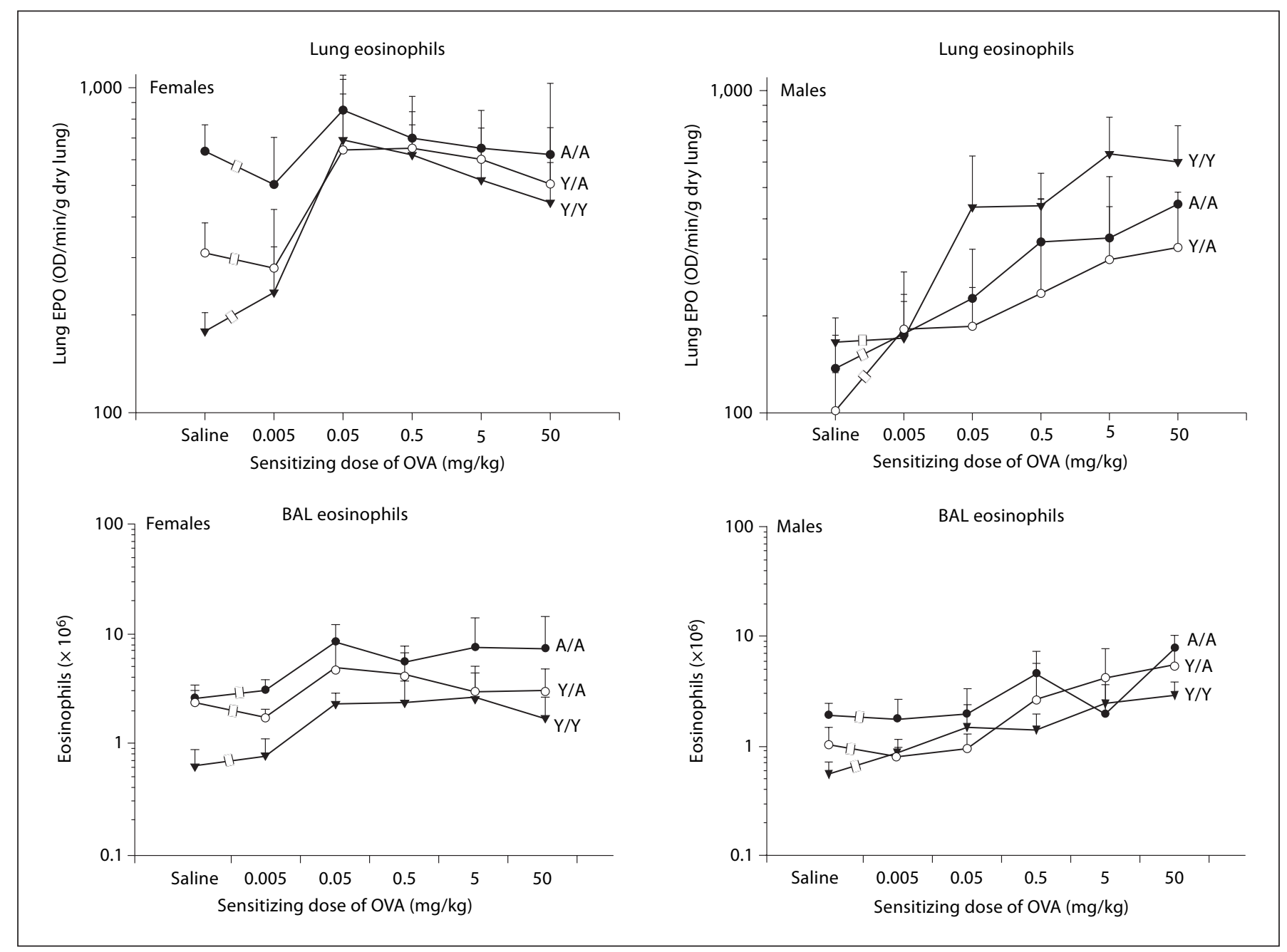

Fig. 1. Eosinophils in the lung and BAL of male and female guinea pigs sensitized with either saline or varying doses of OVA. All animals were challenged with $0.4 \mathrm{mg} / \mathrm{kg}$ OVA intratracheally, and eosinophilia was determined $24 \mathrm{~h}$ after challenge. Details of treatment groups are shown in table 1 . Values represent the geometric mean $\pm \mathrm{SE} . \mathrm{OD}=$ Optical density.

\section{Results}

\section{Inflammatory Cells in Unsensitized Animals}

Data for unsensitized animals (saline) are shown in figures 1-3 as the first point in the dose-response relationship. Statistical analysis of these data determined if resident cell populations differed depending on the age and sex of unsensitized animals. For the analysis of unsensitized animals, Y/A and A/A animals were combined to examine the effect of challenge age. As shown in table 2, a significant sex effect was noted for eosinophils in the lung. This indicated that the number of eosinophils in the lung differed between males and females, with females having more resident eosinophils in lung tissue (fig. 1). Using ANOVA, the statistically significant sex by challenge age interaction seen with lung eosinophils (table 2) indicates that the sex differences noted differ with the age at challenge (young or adult challenge age), with adult females having more resident eosinophils in the lung. Also, as seen in figure 1, unsensitized $\mathrm{Y} / \mathrm{Y}$ animals, whether males or females, had similar numbers of resident eosinophils in the lung and BAL. Analysis of lung neutrophils indicates that adult animals had significantly more tissue neutrophils (table 2). Regardless of sex, 


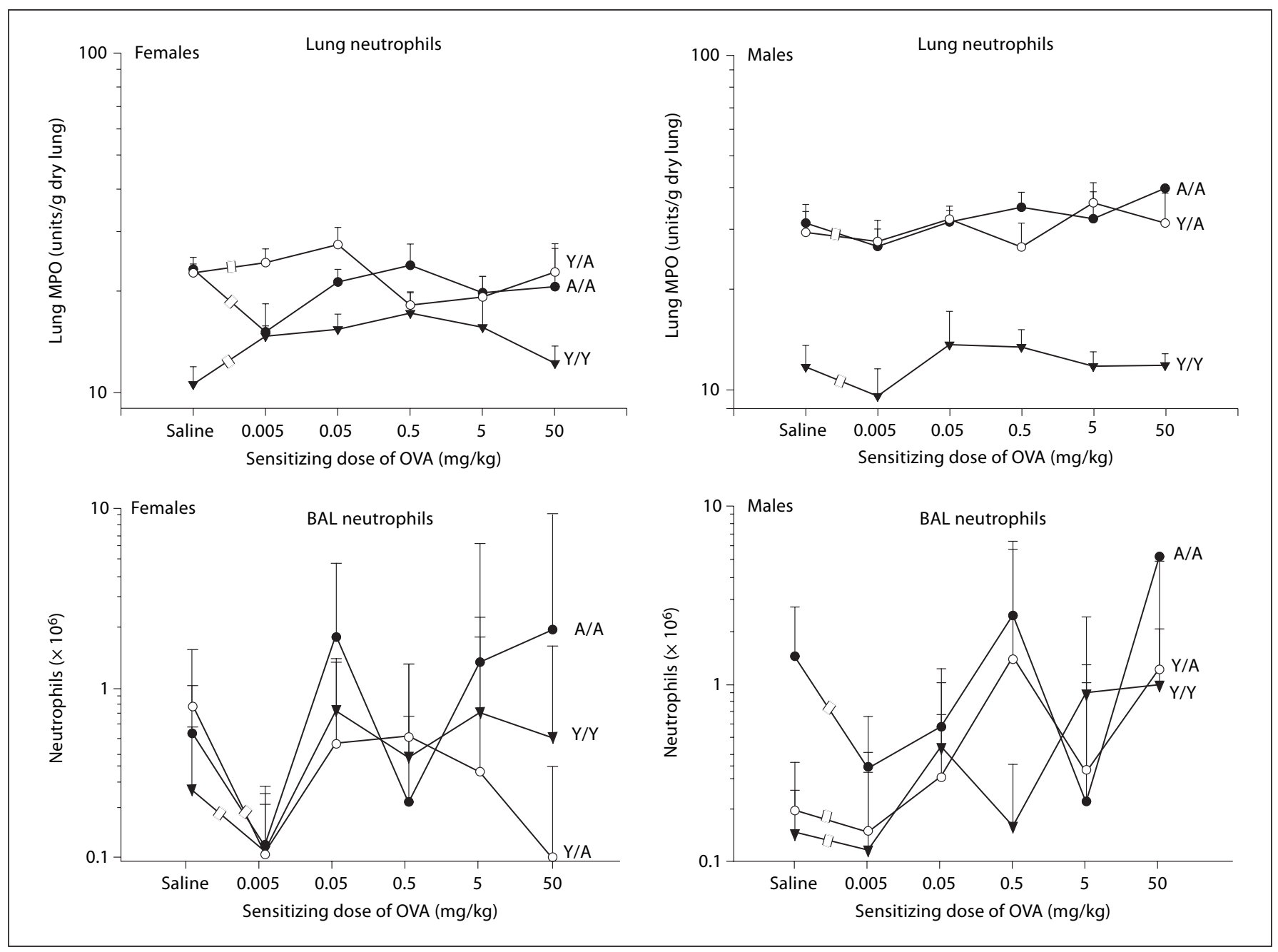

Fig. 2. Neutrophils in the lung and BAL of male and female guinea pigs sensitized with either saline or varying doses of OVA. All animals were challenged with $0.4 \mathrm{mg} / \mathrm{kg}$ OVA intratracheally, and neutrophilia was determined $24 \mathrm{~h}$ after challenge. Details of treatment groups are shown in table 1 . Values represent the geometric mean $\pm S E$.

adult animals also had significantly greater BAL RBC and protein than young animals (fig. 3, table 2), paralleling the results with lung neutrophils. BAL eosinophils and neutrophils were expressed and analyzed as total cells recovered from the BAL. Lung EPO and MPO were adjusted by gram weight of the lung, so the differences noted are not simply due to differences in sizes of the lungs over the range of ages investigated but rather reflect different densities or proportions of inflammatory cells in the lungs of young and adult, male and female animals. Clearly, resident cell populations in the lung tissue and BAL of unsensitized animals differed with challenge age and/or sex.
The Effect of Varying the Sensitizing Dose of OVA on Antigen-Induced Cell Infiltration into the Lung

Guinea pigs were sensitized with varying doses of OVA $(0.005-50 \mathrm{mg} / \mathrm{kg})$, and the dose-response relationships for the 6 different treatment groups are shown in figures 1-3. Since EPO is plotted in the log scale, changes in the log values relative to the initial saline values correspond to ratios of the treated to the saline values in the linear scale. Visual examination of the dose-response relationships, particularly for eosinophils, suggested that the initial change from the unsensitized control to $0.05 \mathrm{mg} / \mathrm{kg}$ differed, as did the slope of the dose-response relationship over the last 4 doses $(0.05-50 \mathrm{mg} / \mathrm{kg})$. Thus, 


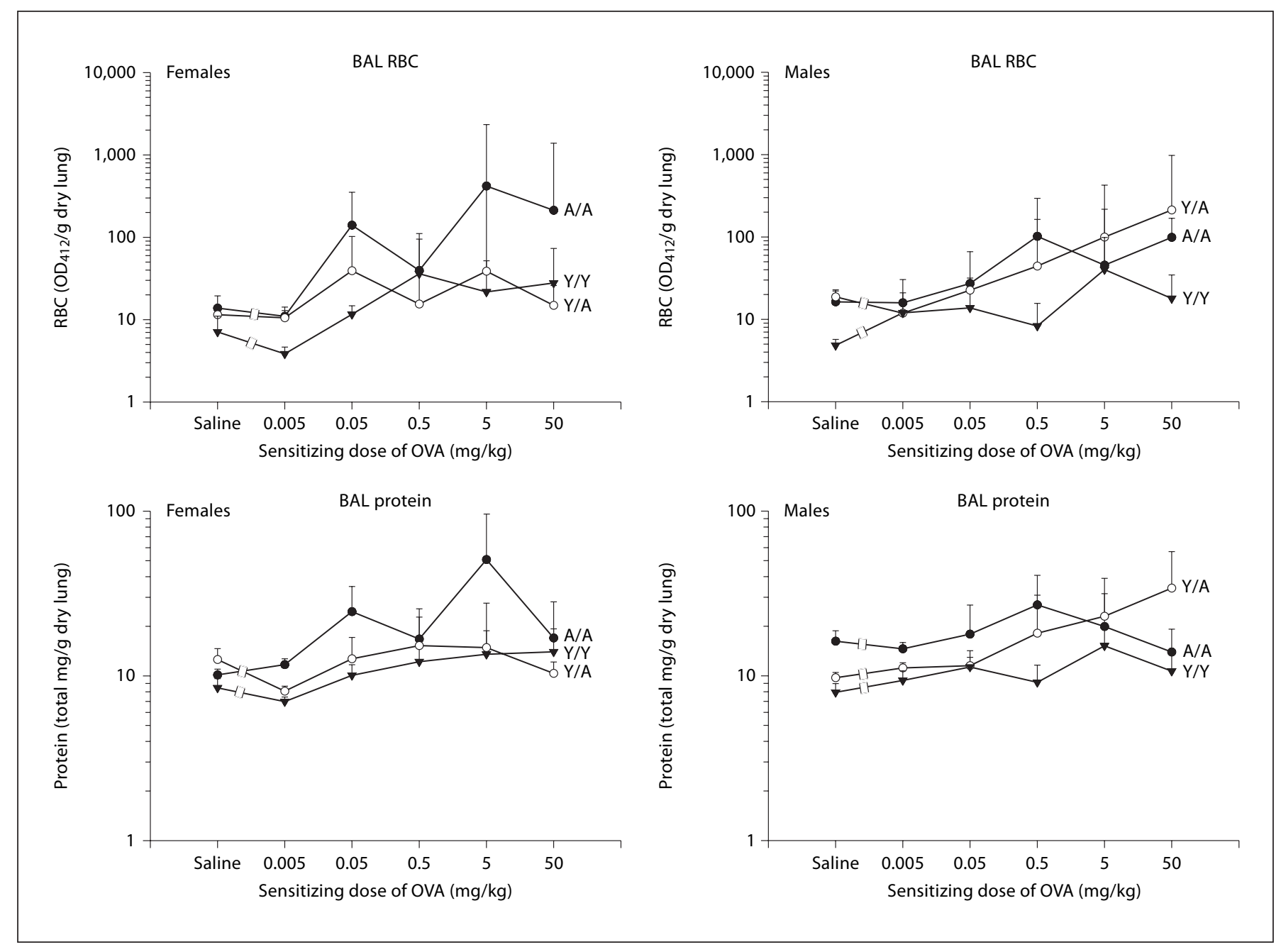

Fig. 3. RBC and protein in the BAL supernatant of male and female guinea pigs sensitized with either saline or varying doses of OVA. All animals were challenged with $0.4 \mathrm{mg} / \mathrm{kg}$ OVA intratracheally, and BAL was obtained $24 \mathrm{~h}$ after challenge. Details of treatment groups are shown in table 1 . Values represent the geometric mean \pm SE. $\mathrm{OD}_{412}=$ Optical density at $412 \mathrm{~nm}$.

analysis of the dose-response relationship was divided into two components. First, the change in each variable from saline to a sensitizing dose of $0.05 \mathrm{mg} / \mathrm{kg}$ OVA was tested for significance. Then, linear regression analyses at sensitizing doses of $0.05-50 \mathrm{mg} / \mathrm{kg}$ OVA were used to test the effects of sex, treatment and dose. Data for macrophages and lymphocytes in the BAL are not shown because significant differences were not detected in any of the analyses.

Eosinophils. The effects of varying the sensitizing dose of OVA on the eosinophilia in both the lung and BAL are shown in figure 1 . As shown in table 2, the change from saline to $0.05 \mathrm{mg} / \mathrm{kg}$ OVA in lung and BAL eosinophils was statistically significant for both male and female $\mathrm{Y} / \mathrm{Y}$ treatment groups. In addition, the female A/A also had a significant increase in eosinophils in the BAL. However, the female Y/A, male Y/A, and male A/A groups did not show significant increases in eosinophils in the lung or BAL over this sensitization dose range.

The changes in lung eosinophils from saline to $0.05 \mathrm{mg} / \mathrm{kg}$ OVA between the 6 different treatment groups were also compared, and significant differences are indicated in table 2. This comparison revealed that the change in lung eosinophils in female $\mathrm{Y} / \mathrm{Y}$ differed from the change in lung eosinophils in female A/A. Additionally, the change in BAL eosinophils in female $\mathrm{Y} / \mathrm{Y}$ was signif- 


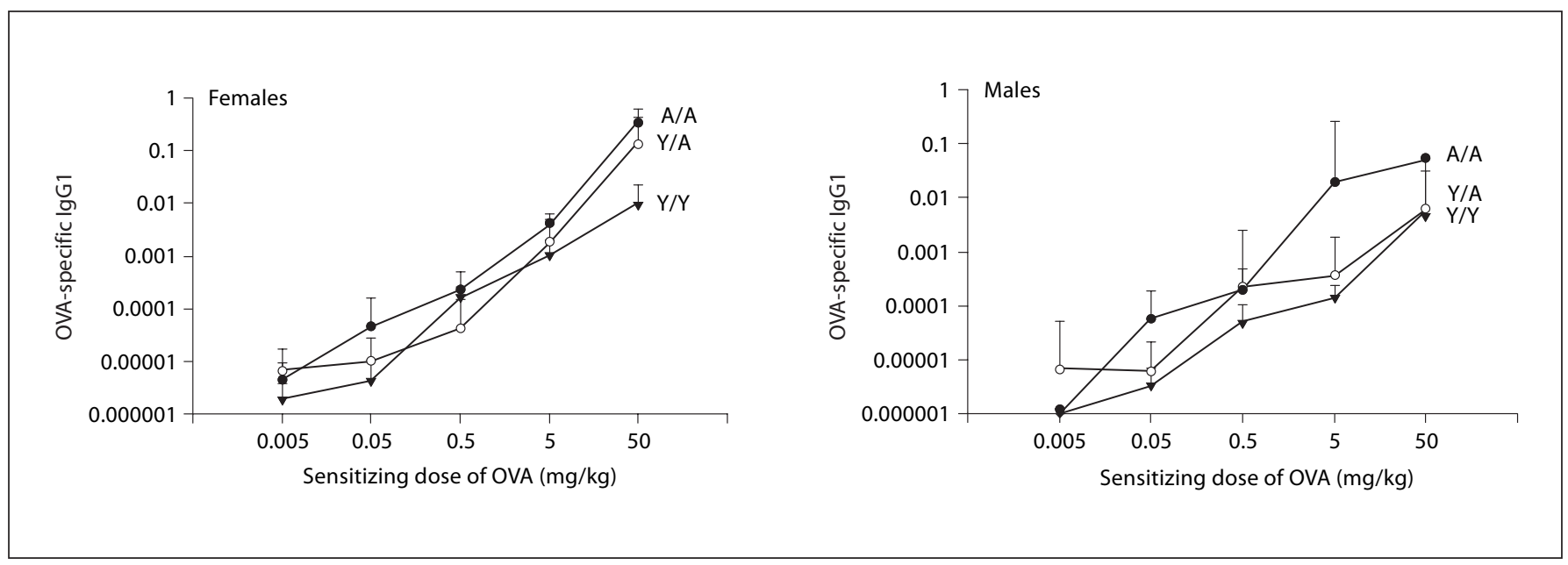

Fig. 4. OVA-specific IgG1 antibody in the serum of animals sensitized with varying doses of OVA. All animals were challenged with $0.4 \mathrm{mg} / \mathrm{kg}$ OVA intratracheally, and serum was obtained $24 \mathrm{~h}$ after challenge. Details of treatment groups are shown in table 1 . Values represent the geometric mean \pm SE.

Table 2. Statistical analysis of doseresponse relationships in figures $1-3$

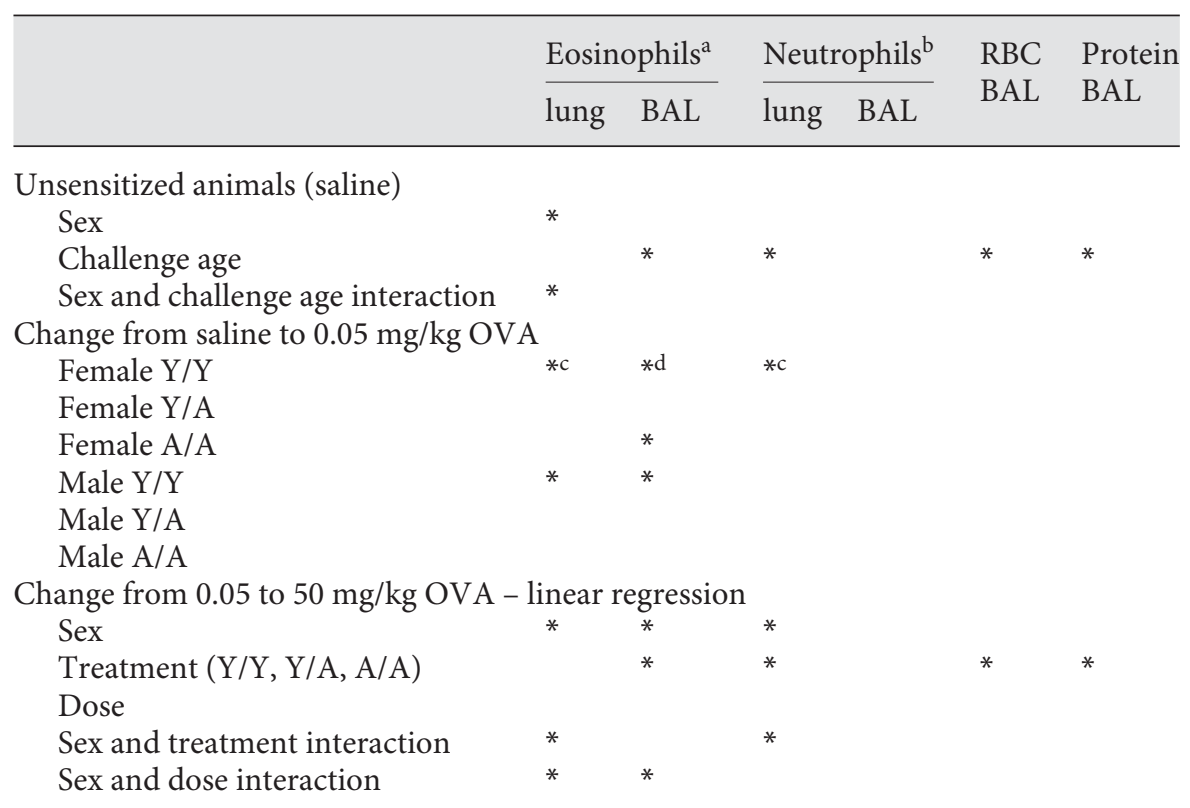

${ }^{*} \mathrm{p}<0.05$ by ANOVA or ANCOVA, as described in statistical analysis.

a Lung eosinophils were estimated by measurement of eosinophil peroxidase of the homogenized lung. BAL eosinophils were determined from cytospin preparations of BAL cells.

${ }^{b}$ Lung neutrophils were estimated by measurement of myeloperoxidase of the homogenized lung. BAL neutrophils were determined from cytospin preparations of BAL cells.

c Significantly greater than the change seen in female A/A.

$\mathrm{d}$ Significantly greater than the change seen in Y/A males or A/A males. 
icantly different from the change in BAL eosinophils in male Y/A and male A/A. Thus, the Y/Y females had a more pronounced change in eosinophils relative to their respective saline values compared with many of the adult treatment groups. These were the only statistically significant contrasts detected and led to the general conclusion that $\mathrm{Y} / \mathrm{Y}$ females had a greater increase in eosinophils than adult animals in general.

Linear regression analyses of the lung and BAL eosinophils over the dose range $0.05-50 \mathrm{mg} / \mathrm{kg}$ detected a significant sex effect as well as a significant sex by dose interaction (table 2). This analysis indicates that the slope of the dose-response relationship differs between males and females for both lung and BAL eosinophils. The sensitizing dose that caused maximum eosinophilia for females was significantly less than that for males. In addition, a significant sex by treatment interaction was detected for lung eosinophils indicating that the eosinophils in the different treatment groups differed by sex. The treatment effect seen with BAL eosinophils likely reflects the fewer numbers of total BAL cells that are recovered from smaller animals $(\mathrm{Y} / \mathrm{Y})$.

Neutrophils. The effects of varying the sensitizing dose of OVA on the neutrophils in both the lung and BAL are shown in figure 2. With lung and BAL neutrophils, the only significant change from saline to the $0.05 \mathrm{mg} / \mathrm{kg}$ OVA-sensitizing dose was seen in lung neutrophils of $\mathrm{Y} / \mathrm{Y}$ females (table 2). Otherwise, the changes in neutrophils over this dose range were not significant in any other treatment group. When the change in lung neutrophils in $\mathrm{Y} / \mathrm{Y}$ females was compared with changes in other treatment groups, Y/Y females differed from the A/A females only (table 2). These results indicate that young females have a more pronounced initial change in lung neutrophils compared with adult females.

Linear regression analyses of the lung and BAL neutrophils over the dose range of $0.05-50 \mathrm{mg} / \mathrm{kg}$ detected significant sex, treatment group and sex by treatment group interaction effects with lung neutrophils (table 2). This suggested that adult animals, particularly males, have more tissue neutrophils. No significant dose effects were seen, consistent with the shape of the dose-response relationships for the different treatment groups shown in figure 2 .

$R B C$ and Protein in the BAL. The effects of varying the sensitizing dose of OVA on RBC and protein in the BAL are shown in figure 3. No significant changes from unsensitized animals to animals sensitized with $0.05 \mathrm{mg} / \mathrm{kg}$ OVA in either RBC or protein were detected in any of the 6 treatment groups (table 2). Because of the shape of the dose-response relationship, we also examined these data for significant changes over the complete dose range, i.e. from unsensitized animals to animals sensitized with $50 \mathrm{mg} / \mathrm{kg}$. With this analysis, a significant change from unsensitized to $50 \mathrm{mg} / \mathrm{kg}$ OVA was detected for RBC in the BAL for female A/A, male Y/Y and male Y/A (results of statistical analysis not shown). Additionally, for protein in the BAL supernatant, a significant change from unsensitized animals to $50 \mathrm{mg} / \mathrm{kg}$ OVA was seen for female $\mathrm{Y} / \mathrm{Y}$ and male $\mathrm{Y} / \mathrm{A}$ treatment groups (results of statistical analysis not shown). Linear regression analyses of the $\mathrm{RBC}$ and protein in the BAL over the dose range $0.05-50 \mathrm{mg} / \mathrm{kg}$ detected significant treatment effects for both $\mathrm{RBC}$ and protein in the BAL. These data suggest that adult animals incurred more lung injury than young animals after antigen challenge. This paralleled the treatment effect seen in lung neutrophils over this sensitizing dose range. In addition, when the protein in the BAL supernatant and the number of RBC in the BAL fluid were evaluated, both males and females challenged as adults had significantly greater numbers, suggesting that lung damage more readily occurred in this age group.

\section{OVA-Specific Antibody Levels}

Clearly, age and sex affected the cellular infiltration into the guinea pig lung. In order to determine if these differences were due to the differential production of OVA-specific antibody by animals in the different treatment groups, we measured the serum concentration of OVA-specific IgG1. The effect of varying the sensitizing dose of OVA on the OVA-specific IgG1 concentration in the serum is shown in figure 4. ANOVA was conducted to test for effects of dose, sex, treatment, and their interactions. A statistically significant dose-dependent increase for OVA-specific IgG1 in the serum was seen in all treatment groups (Y/Y, Y/A, A/A). In addition, a significant treatment group effect was noted, but not a significant effect of sex or a sex by treatment group interaction. Thus, both males and females had similar concentrations of OVA-specific IgG1 in any given treatment group, but the concentration of circulating antibody differed with treatment groups.

To determine if the concentration of OVA-specific IgG1 accounted for differences in cellular infiltration noted with age and sex, correlations were computed between antibody levels and the measurements of eosinophils and neutrophils in the lung and BAL. When each of the variables was plotted versus OVA-specific IgG1, statistically significant correlations were detected for all but the lung neutrophil data (data not shown). However, the 


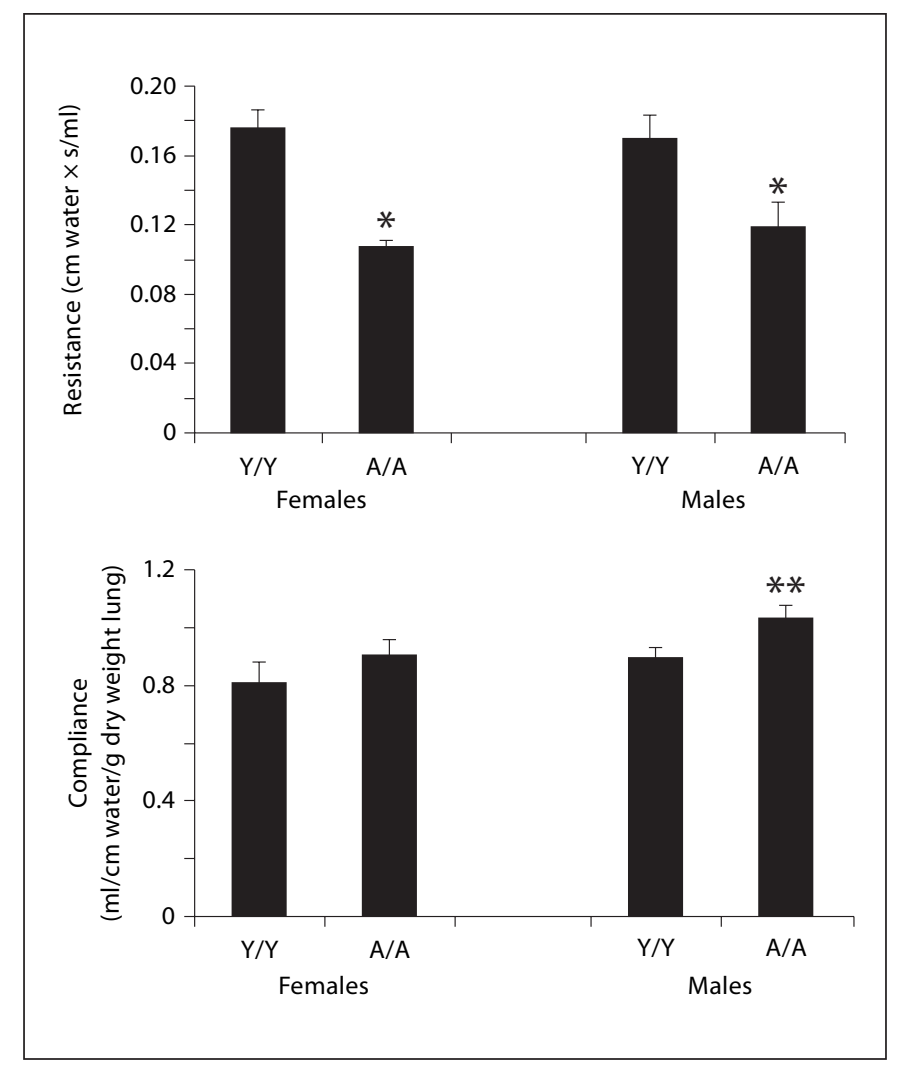

Fig. 5. Baseline resistance and compliance in male and female guinea pigs sensitized with saline and challenged with $0.4 \mathrm{mg} / \mathrm{kg}$ OVA intratracheally $24 \mathrm{~h}$ before measurement. Details of treatment groups are shown in table 1 . Values represent the mean \pm SE. ${ }^{*} \mathrm{p}<0.05$ compared with $\mathrm{Y} / \mathrm{Y}$ animals, whether males or females; ${ }^{* *} \mathrm{p}<0.05$ compared with Y/Y females only. Other comparisons were not significant.

$r^{2}$ values indicated minimal biological significance of the correlations because they were very small, ranging from only 0.03 to 0.10 .

Differences in antibody production amongst treatment groups were not related to the differences in OVAinduced cellular infiltration noted with age and sex (fig. 1-3). For example, female A/A animals had the highest concentrations of OVA-specific antibody over the dose range but had minimal changes in lung eosinophils over the same dose range. Female Y/Y guinea pigs had the most striking increase in lung eosinophils from the unsensitized controls at the $0.05 \mathrm{mg} / \mathrm{kg}$ sensitizing dose. However, the OVA-specific antibody at this $0.05 \mathrm{mg} / \mathrm{kg}$ sensitizing dose in $\mathrm{Y} / \mathrm{Y}$ females was less than that in $\mathrm{A} / \mathrm{A}$ females. Clearly, the OVA-specific IgG1 did not predict the eosinophil infiltration in a specific age or sex group.

\section{The Effects of Age and Sex on Antigen-Induced} Airway Hyperresponsiveness

Airway hyperresponsiveness to methacholine was assessed in $\mathrm{Y} / \mathrm{Y}$ and $\mathrm{A} / \mathrm{A}$ male and female animals sensitized with either saline or $0.5 \mathrm{mg} / \mathrm{kg}$ OVA and challenged with $0.4 \mathrm{mg} / \mathrm{kg}$ OVA. These doses and treatment groups were chosen because a significant change in tissue eosinophil accumulation from saline to OVA-sensitized animals was demonstrated in $\mathrm{Y} / \mathrm{Y}$ females but not in $\mathrm{A} / \mathrm{A}$ females (fig. 1, table 2). In both $\mathrm{Y} / \mathrm{Y}$ and A/A male animals, the maximal eosinophilia had not been attained at this sensitizing dose of OVA. Thus, the severity of the airway hyperresponsiveness would be expected to range from minimal in female A/A animals to very severe in female $\mathrm{Y} / \mathrm{Y}$ animals if airway hyperresponsiveness was directly related to the accumulation of eosinophils relative to saline baseline levels in the lung tissue.

In figure 5, baseline measurements of resistance and compliance are shown for animals sensitized with saline and challenged with OVA, prior to intravenous administration of vehicle or methacholine. Young animals whether male or female had significantly higher baseline resistance than adult animals. Baseline compliance was normalized for lung size (per gram dry lung). No significant differences in compliance were detected except when comparing $\mathrm{Y} / \mathrm{Y}$ females with A/A males.

Airway hyperresponsiveness to intravenously administered vehicle and 2 successive doses of methacholine is reported in figure 6 . In general, the magnitude of the change in resistance or compliance due to vehicle injection itself was negligible (less than 5\% change from baseline values depicted in fig. 5). Vehicle treatment was compared in saline versus OVA-sensitized animals by ANOVA analysis of all age and sex groups combined, and a significant effect of OVA sensitization was detected overall for resistance and compliance. Individual contrasts were then conducted and indicated that the difference in vehicle, comparing saline and OVA-sensitized animals, was significant in female A/A animals for resistance, and in female and male A/A animals for compliance (** in fig. 6). This OVA effect on compliance and resistance in the vehicle group is likely due to a residual effect of intratracheal antigen delivery $24 \mathrm{~h}$ prior to the measurement of methacholine reactivity.

In the evaluation of methacholine reactivity in saline versus OVA-sensitized animals, statistical analysis used a repeated measures analysis evaluating the change in resistance and compliance from both 0.001 and $0.0033 \mathrm{mg} /$ $\mathrm{kg}$ methacholine to vehicle. This type of analysis was used because of the significant OVA sensitization effect 
Fig. 6. Methacholine induced changes in resistance and compliance in male and female guinea pigs sensitized with either saline or $0.5 \mathrm{mg} / \mathrm{kg}$ OVA. All animals were challenged with $0.4 \mathrm{mg} / \mathrm{kg}$ OVA intratracheally, and responsiveness to vehicle (PBS/heparin) and 2 successive doses of intravenous methacholine were determined $24 \mathrm{~h}$ after challenge. Details of treatment groups are shown in table 1 . Values represent the geometric mean \pm SE. ${ }^{*} \mathrm{p}<0.05$, significant overall OVA effect with repeated measures ANOVA; ${ }^{* *} \mathrm{p}<$ 0.05 , vehicle response in animals sensitized with OVA is greater than the vehicle response in animals sensitized with saline.
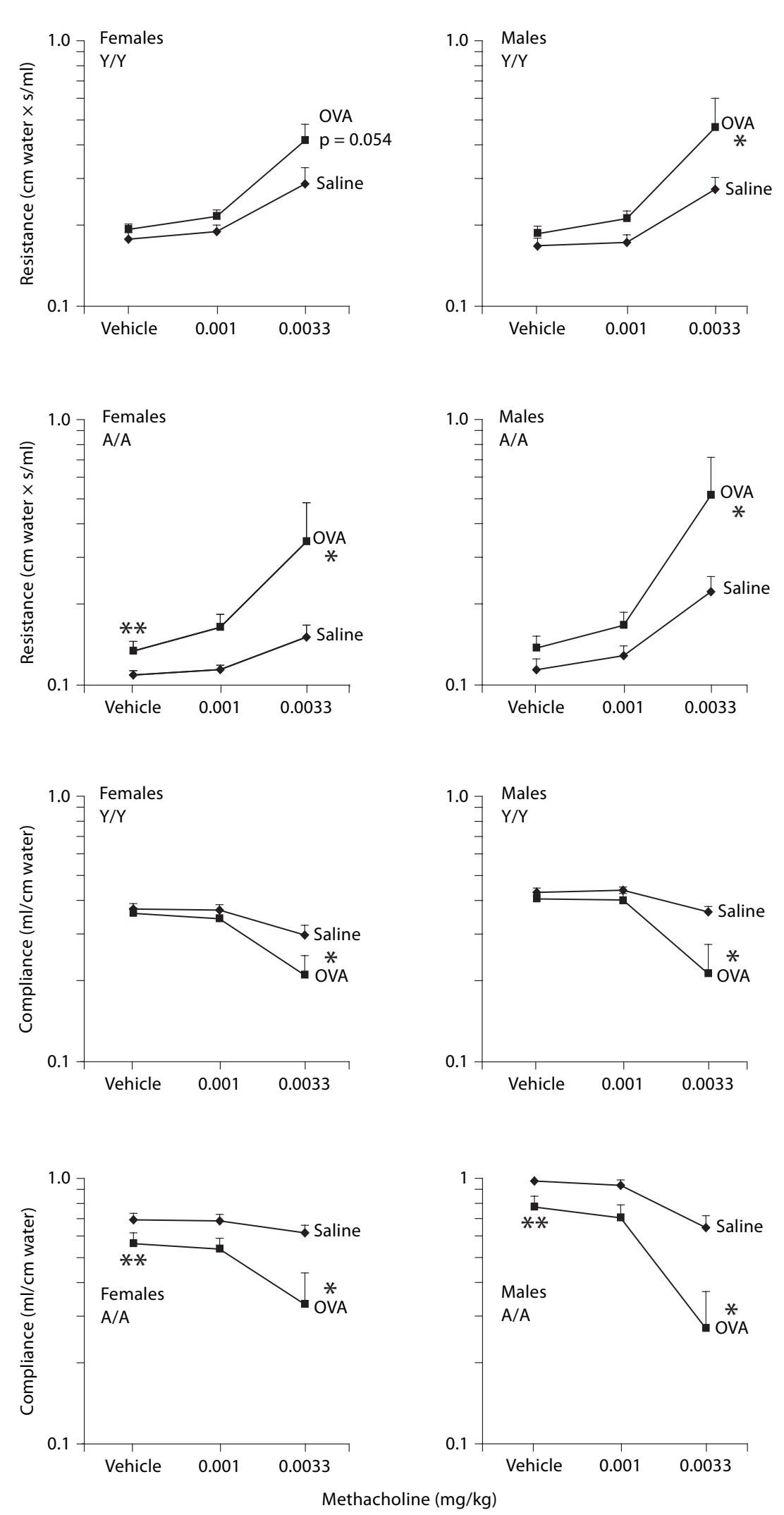
in the vehicle group of the A/A treatment groups. When considering increased resistance and decreased compliance to the 2 successive doses of methacholine, all 4 groups of animals demonstrated increased reactivity to methacholine after OVA sensitization compared with saline sensitization (* in fig. 6). For the OVA effect on pulmonary resistance, the $\mathrm{Y} / \mathrm{Y}$ females with a $\mathrm{p}=0.054 \mathrm{did}$ not meet the statistical cutoff of $p=0.05$. However, the $p$ value suggested a potential OVA effect for this particular treatment group. The increased reactivity to methacholine in OVA-sensitized animals tended to be greater in adult animals compared with young animals. However, these comparisons were not statistically significant on further analysis.

\section{Discussion}

The purpose of the present study was to systematically determine if limiting allergen exposure in the sensitization phase (primary prevention) would be a more effective strategy of asthma control in certain age or sex groups. We hypothesized that primary prevention is more effective in limiting asthma symptoms in young animals compared with adults, whether males or females. In considering allergic airway inflammation, the sensitization dose resulting in eosinophil infiltration into the lung varied significantly with the age and sex of the animal. The differences in the dose-response relationships for sensitizing dose and lung eosinophils are striking when comparing males and females. The males have a gradual increase in eosinophils as the sensitizing dose increases, whereas the increase in the females is exceedingly abrupt. Young females exhibited an increase in eosinophils and neutrophils at the lowest allergen doses. Thus, major reductions in allergen exposure would be required to affect the extent of airway inflammation in young animals, particularly females. Lesser reductions in allergen exposure during the sensitization phase would minimize airway inflammation in adult males. Airway inflammation in adult females was minimal over the allergen range tested, and thus, reducing allergen load would not be useful in this group for reducing airway inflammation. In a primary prevention strategy of asthma control, these data indicate that different reductions in allergen load are required to limit airway inflammation in specific age and gender populations.

Airway hyperresponsiveness was only assessed in selected groups of young and adult animals at a single sensitizing dose and therefore do not provide complete information regarding primary prevention of airway hyperresponsiveness. Airway hyperresponsiveness to methacholine was observed at a sensitizing dose of OVA that resulted in widely different accumulations of eosinophils in the different age and sex groups. OVA sensitization tended to increase methacholine reactivity to a greater degree in adult animals than in young animals, particularly in $\mathrm{Y} / \mathrm{Y}$ females. However, the differences in methacholine reactivity in OVA-sensitized animals were not statistically different between the treatment groups. These contrasting profiles of eosinophil infiltration and airway hyperresponsiveness suggest that age and sex contribute to asthma heterogeneity. For example, A/A females did not accumulate eosinophils compared with saline levels in the lung tissue at any of the sensitizing doses but showed very significant airway hyperresponsiveness after OVA sensitization. In contrast, eosinophil infiltration relative to saline levels in $\mathrm{Y} / \mathrm{Y}$ females was very high, but the airway hyperresponsiveness to methacholine after OVA sensitization in this age and sex group was low. In addition, adult animals tended to have more protein and $\mathrm{RBC}$ in the lavage fluid, suggesting a greater propensity to lung injury in the adult animals. Thus, the heterogeneity of asthma is reflected in these different profiles of asthma symptoms (inflammation vs. airway obstruction) in different age and sex groups in this guinea pig model.

How do these studies relate to asthma in humans? Asthma is increasingly recognized as a heterogeneous lung disorder. Numerous asthma phenotypes have been described including eosinophilic, noneosinophilic, IgEmediated, and steroid-resistant asthma [21, 22]. Many debate whether the best indicator of asthmatic status is inflammation or pulmonary function. Certainly, asthma therapy targets both the inflammatory component (steroids) and the airway obstruction component (bronchodilators). A recent study found that children with severe asthma had less severe airflow obstruction compared with adults with asthma [23]. A number of children who were experiencing life-threatening asthma episodes had $\mathrm{FEV}_{1}$ values of $>80 \%$. Thus, other factors such as inflammation were likely contributing to the disease severity. The concern clinically is that the severity of the child's asthma may not be realized by pulmonary function testing resulting in undertreatment. Similarly, in the guinea pig model, the young animals tended to have less airway hyperresponsiveness than the adults, but greater eosinophil accumulation into the lung at a given sensitizing dose. Our studies clearly demonstrate that in the guinea pig model, the profiles of airway hyperresponsiveness 
and airway inflammation differ with age and sex. Optimal therapy for asthma may need to specifically target inflammation or airway obstruction depending on age and sex.

The relationship of eosinophil accumulation and airway hyperresponsiveness has long been debated, and the benefit of treating asthma in humans with anti-inflammatory drugs versus bronchodilators has a controversial history [24]. In our study, increases (or lack of increases) in the eosinophils in the lung tissue or BAL were not connected with corresponding degrees of airway hyperresponsiveness. Studies of others in mice and guinea pigs have provided evidence both for and against a causative relationship between eosinophils and airway dysfunction in these animal models [25-28]. The timing and chronicity of eosinophilia, the state of eosinophil activation, and the extent of airway remodeling have been considered as potentially important factors in the development of airway hyperresponsiveness. Our studies examined both the airway compartment as well as the tissue compartment for increases in eosinophils, since the relative importance of eosinophils in the airway lumen versus the tissue space in the pathophysiology of asthma is unclear. A recent study by Fryer et al. [29] provides strong evidence in a guinea pig model using adult females that accumulation of eosinophils adjacent to the airway nerve and the resultant M2 receptor dysfunction are critical to the development of airway hyperresponsiveness.

Comparing the allergic response in male and female animals, Corteling and Trifilieff [12] noted minimal differences in BAL cell infiltration following OVA sensitization and challenge but described a two-fold increase in total serum IgE in female mice compared with males. In an earlier study, Hayashi et al. [11] reported that male mice had a decreased Th2 cell response and less airway inflammation than females in an OVA model of asthma. In our study with the guinea pig, the maximum eosinophil infiltration was similar in males and females, but the slopes of the dose-response relationships differed.

Puberty in humans is the stage of physical maturation during which an individual becomes capable of sexual reproduction. In humans, $95 \%$ of girls begin puberty at an average age of 10.5 years and boys at 11.5 years [10]. Sexual development is completed in 4.2 years for girls and 3.5 years for boys. Thus, the age range of 10-16 years defines the age at which sexual maturation is occurring in humans. In the present study, a young animal, after weaning and before sexual maturity, is used as a model of a child. A sexually mature animal is used as a model of an adult.

Age and Sex Differences in Asthma
Comparing the allergic response in young versus adult animals, Gelfand et al. [30] reported that the age of the mouse at initial sensitization was the critical factor determining the response to later allergen challenge. Mice sensitized at 8 weeks and challenged at 34 weeks exhibited a significantly greater asthmatic response than animals sensitized at 30 weeks and challenged at 34 weeks. Over the more limited age range of our study in the guinea pig, the time of initial sensitization (young or adult) did not dictate the magnitude of the response. Another study comparing the magnitude of the allergic response in mice sensitized at 3 days versus 8 weeks after birth saw minimal differences in allergic inflammation and airway hyperresponsiveness [31].

The effects of age on the in vitro and in vivo bronchoconstrictor responses to leukotrienes, histamine, thromboxane, bradykinin, and substance $\mathrm{P}$ have been studied in the guinea pig; however, a consistent pattern has not emerged. The sensitivities of mature and immature animals differ with different bronchoconstrictors [32-37]. Chitano and Murphy [38] have extensively studied maturational changes in isolated airway smooth muscle in male guinea pigs and demonstrated increased acetylcholine reactivity from birth to 2 weeks followed by a decline from 2 to 12 weeks. Thus, differences in airway responsiveness to methacholine in our study in vivo may be a combination of age and sex differences in initial resistance and compliance, reflex bronchoconstriction, cholinergic reactivity of smooth muscle, as well as differences in the influence of allergen challenge in vivo.

Studies assessing the complete allergen dose response in animals are limited. In a murine model of asthma [39] using 6- to 8-week-old female animals, eosinophil infiltration, airway hyperresponsiveness and IgE production decreased as the sensitization dose of OVA increased. Studies in the guinea pig over a limited dosing range of cockroach allergen demonstrated a relationship between the dose of allergen and antibody production, but the severity of asthma as measured by bronchoconstriction was not dose related over the same allergen range [40].

Previous studies have examined differences in pulmonary function with age and noted higher baseline resistance in immature versus mature guinea pigs [14], just as in our studies. In addition, past studies have noted that baseline compliance was less in young guinea pigs of mixed sexes (4 days) compared with older animals $(\geq 4$ weeks) [41] after correcting for lung weight. In our study, compliance in young females (4 weeks) was statistically different than in adult males ( 15 weeks) after correcting for lung weight. Because of the known dependence of 
compliance on lung volume, in studies comparing animals of widely different sizes, it is common to normalize compliance by parameters such as body weight or lung weight since they are readily measured and relate to the lung volume of the animal [41-43].

Resident cell populations in the lungs of male and female, young and adult animals differed significantly in both the airspace (BAL cells) and the tissue compartment (lung EPO and MPO). Particularly striking was the high proportion of eosinophils in the lungs of unsensitized adult female guinea pigs and the high number of neutrophils in adult animals, males and females. Studies in the normal aging human lung have also noted an accumulation of inflammatory cells, particularly neutrophils [44]. However, increased eosinophils were not noted in aging humans.

Many published studies using the guinea pig as a model of asthma use 250- to 500-gram animals with large sensitizing doses of OVA (1-10 $\mathrm{mg} / \mathrm{kg}$ range) with the addition of adjuvant to ensure that eosinophil infiltration into the lung is apparent with antigen challenge [45-48]. Our studies used significantly lower sensitizing doses of OVA and clearly indicate that in situations where the allergen exposure is limited during the sensitization phase, in the lower range of the dose-response relationship, the magnitude of eosinophil infiltration varies with age and sex of the guinea pig. In addition, in studies where adult females are used, an accumulation of eosinophils in the lung may be difficult to demonstrate at low allergen doses in the absence of adjuvant. The present study used outbred guinea pigs as an asthma model, and variability in the measurement of cellular infiltration was similar to other published studies. The study design controlled for environmental exposures. That is, all animals (Y/Y, Y/A and $\mathrm{A} / \mathrm{A}$ ) were shipped to our animal facility at postnatal day 7 , and thus, were exposed to the same conditions as they matured. Therefore, differences in environmental exposures did not account for the variability seen in this study.

Choice of animal models and how they reflect the situation in the human are always debated. An advantage of the guinea pig model of asthma is that eosinophil infiltration into the lung readily occurs. Additionally, the guinea pig readily produces antibody to OVA in the absence of adjuvant. A disadvantage is that guinea pigs do not readily produce IgE antibody like humans but produce cytophilic IgG1 antibody. We also considered that OVA-specific IgG2 in the guinea pig may affect the response. However, OVA-specific IgG2 was only detectable in the serum at the 2 highest sensitizing doses of OVA with minimal difference between the antibody levels at these two doses (data not shown) in any treatment group. Thus, differences in IgG2 do not directly relate to differences in eosinophil accumulation and airway hyperresponsiveness. With OVA-specific IgG1, our studies demonstrated that over the sensitizing dose range examined, guinea pigs produced a dose-related increase in OVA-specific IgG1 antibody, with no detectable difference in antibody production due to sex. The antibody production differed with treatment group, but the differences in antibody production did not directly relate to the differences in antigen-induced eosinophilia seen with age and sex, suggesting that cell-mediated, antibody-independent mechanisms are likely to be important.

Our studies suggest that reducing allergen load during the sensitization phase as a means of primary prevention to limit asthma symptoms would require major reductions in allergen exposure in young animals, particularly females, compared with adult males. Lesser reductions in allergen exposure during the sensitization phase would minimize airway inflammation in adult males. Clearly, age and sex are important components of asthma heterogeneity. The differential sensitivity of different age and sex groups to allergen suggests that the utility of primary prevention or treatment with anti-inflammatory or bronchodilator drugs may be more effective strategies for particular age or gender populations.

\section{Acknowledgments}

This work was supported by a grant from the US Army Medical Research Acquisition Activity DAMD 17-02-1-0191. The US Army Medical Research Acquisition Activity, Fort Detrick, Md., USA, is the awarding and administering acquisition office for this award. The technical assistance of Renee Griffith and Amy Kunze, the animal husbandry provided by Jack Aldrich and Gail Boatman, and the statistical assistance of Mingqian Duan were excellent and are gratefully acknowledged. 


\section{References}

1 Arshad SH: Primary prevention of asthma and allergy. J Allergy Clin Immunol 2005; 116:3-14.

2 Institute of Medicine: Clearing the Air: Asthma and Indoor Air Exposures. Washington, National Academy Press, 2000.

-3 Arbes SJ, Cohn DR, Yin M, Muilenberg ML, Burge HA, Friedman W, Zeldin DC: House dust mite allergen in US beds: results from the first national survey of lead and allergens in housing. J Allergy Clin Immunol 2003; 111:408-414.

4 Woodcock A, Forster L, Matthews E, Martin J, Letley L, Vickers M, Britton J, Strachan D, Howarth P, Altmann D, Frost C, Custovic A: Control of exposure to mite allergen and allergen-impermeable bed covers for adults with asthma. N Engl J Med 2003;349:221232.

5 Allmers H, Schmengler J, Skudlik C: Primary prevention of natural rubber latex allergy in the German health care system through education and intervention. J Allergy Clin Immunol 2002;110:318-323.

6 Baur X: Are we closer to developing threshold limit values for allergens in the workplace? Ann Allergy Asthma Immunol 2003; 90(suppl):11-18.

7 Chan-Yeung M, Ferguson A, Watson W, Dimich-Ward H, Rousseau R, Lilley M, DyBuncio A, Becker A: The Canadian Childhood Asthma Primary Prevention Study: outcomes at 7 years of age. J Allergy Clin Immunol 2005;116:49-55.

$>8$ King ME, Mannino DM, Holguin F: Risk factors for asthma incidence: a review of recent prospective evidence. Panminerva Med 2004;46:97-111.

-9 Simpson A, Custovic A: Allergen avoidance in the primary prevention of asthma. Curr Opin Allergy Clin Immunol 2004;4:45-51.

10 Zannolli R, Morgese G: Does puberty interfere with asthma? Med Hypotheses 1997;48: 27-32.

-11 Hayashi T, Adachi Y, Hasegawa K, Morimoto $\mathrm{M}$ : Less sensitivity for late airway inflammation in males than females in Balb/c mice. Scand J Immunol 2003;57:562-567.

$\checkmark 12$ Corteling R, Trifilieff A: Gender comparison in a murine model of allergen-driven airway inflammationand theresponsetobudesonide treatment. BMC Pharmacol 2004;4:4.

-13 Larsen CP, Regal JF: Trimellitic anhydrideinduced cellular infiltration into guinea pig lung varies with age but not gender. Int Arch Allergy Appl Immunol 2002;127:63-72.

-14 Arakawa H, Tokuyama K, Mochizuki H, Morikawa A, Lötvall J: Effect of maturation on allergen-induced airflow obstruction and airway plasma exudation in sensitized guinea pigs. Int Arch Allergy Appl Immunol 1997;112:196-202.
15 Lemanske RF, Busse WW: Asthma. J Allergy Clin Immunol 2003;111:S502-S519.

16 Charles River Laboratories: Technical Bulletin, ed 2. Wilmington, Charles River Laboratories, 1999, vol 1, No 1.

17 Fraser DG, Regal JF, Arndt ML: Trimellitic anhydride-induced allergic response in the lung: role of the complement system in cellular changes. J Pharmacol Exp Ther 1995. 273:793-801.

- 18 Lowry OJ, Rosebrough NJ, Farr AL, Randall PJ: Protein measurement with the Folin phenol reagent. J Biol Chem 1951;193:265-275.

19 Fraser DG, Graziano FM, Larsen CP, Regal JF: The Role of IgG1 and IgG2 in trimellitic anhydride-induced allergic response in the guinea pig lung. Toxicol Appl Pharmacol 1998;150:218-227.

20 Regal JF, Fraser DG, Weeks CE, Greenberg NA: Dietary phytoestrogens have anti-inflammatory activity in a guinea pig model of asthma. Proc Soc Exp Biol Med 2000;223: 372-378.

21 Miranda C, Busacker A, Balzar S, Trudeau J, Wenzel SE: Distinguishing severe asthma phenotypes: role of age at onset and eosinophilic inflammation. J Allergy Clin Immunol 2004;113:101-108

22 Bel EH: Clinical phenotypes of asthma. Curr Opin Pulm Med 2004;10:44-50.

23 Jenkins HA, Cherniack R, Szefler SJ, Covr R, Gelfand EW, Spahn JD: A comparison of the clinical characteristics of children and adults with severe asthma. Chest 2003;124:1318 1324.

24 Morley J: Inflammation and asthma therapy: a false dawn. Pulm Pharmacol Ther 2006; 19:200-204.

25 Shen HH, Ochkur SI, McGarry MP, Crosby JR, Hines EM, Borchers MT, Wang H, Biechelle TL, O’Neill RK, Ansay TL, Colbert DC, Cormier SA, Justice JP, Lee NA, Lee JJ: A causative relationship exists between eosinophils and the development of allergic pulmonary pathologies in the mouse. J Immunol 2003;170:3296-3305.

26 Tomkinson A, Cieslewicz G, Duez C, Larson KA, Lee JJ, Gelfand EW: Temporal association between airway hyperresponsiveness and airway eosinophilia in ovalbumin-sensitized mice. Am J Respir Crit Care Med 2001;163:721-730.

27 Santing RE, Olymulder CG, Zaagsma J, Meurs H: Relationships among allergen-induced early and late-phase airway obstruction, bronchial hyperreactivity and inflammation in conscious unrestrained guinea pigs. J Allergy Clin Immunol 1994;93:10211030
28 Santing RE, Hoekstra Y, Pasman Y, Zaagsma J, Meurs H: The importance of eosinophil activation for the development of allergen-induced bronchial hyperreactivity in conscious, unrestrained guinea pigs. Clin Exp Allergy 1994;24:1157-1163.

29 Fryer AD, Stein LH, Nie Z, Curtis DE, Evans CM, Hodgson ST, Jose PJ, Belmonte KE, Fitch E, Jacoby DB: Neuronal eotaxin and the effects of CCR3 antagonist on airway hyperreactivity and $\mathrm{M} 2$ receptor dysfunction. J Clin Invest 2006;116:228-236.

>30 Gelfand EW, Joetham A, Cui ZH, Balhorn A, Takeda K, Taube C, Dakhama A: Induction and maintenance of airway responsiveness to allergen challenge are determined at the age of initial sensitization. J Immunol 2004; 173:1298-1306

31 Ohki Y, Tokuyama K, Mayuzumi H, Sato A, Koyama H, Takizawa T, Arakawa H, Mochizuki H, Morikawa A: Characteristic features of allergic airway inflammation in a murine model of infantile asthma. Int Arch Allergy Immunol 2005;138:51-58.

32 Brink C, Duncan PG, Midzenski M, Douglas JS: The response and sensitivity of female guinea-pig respiratory tissues to agonists during ontogenesis. J Pharmacol Exp Ther 1980;215:426-433.

33 Duncan PG, Douglas JS: Influences of gender and maturation on responses of guineapig airway tissues to $\mathrm{LTD}_{4}$. Eur J Pharmacol 1985;112:423-427.

34 Arakawa H, Tokuyama K, Yokoyama T, Mochizuki H, Morikawa A, Kuroume T, Barnes PJ: Effect of maturation on histamine-induced airflow obstruction and airway microvascular leakage in guinea pig airways. Eur J Pharmacol 1992;215:51-56.

35 Arakawa H, Lötvall J, Kawikova I, Tokuyama K, Löfdahl CG, Skoogh BE: Effect of maturation on airway plasma exudation induced by eicosanoids in guinea pig. Eur J Pharmacol 1994;259:251-257.

-36 Tokuyama K, Yokoyama T, Morikawa A, Mochizuki H, Kuroume T, Barnes PJ: Attenuation of tachykinin-induced airflow obstruction and microvascular leakage in immature airways. Br J Pharmacol 1993;108: 23-29.

37 Yokoyama T, Tokuyama K, Morikawa A, Juroume T: Bradykinin is less potent in causing airway microvascular leakage in immature than in adult guinea-pigs. Role of neutral endopeptidase. Eur J Pharmacol 1993;236:427432

38 Chitano P, Murphy TM: Maturational changes in airway smooth muscle shortening and relaxation. Implications for asthma. Respir Physiol Neurobiol 2003;137:347-359.

-39 Sakai K, Yokoyama A, Kohno N, Hiwada K: Effect of different sensitizing doses of antigen in a murine model of atopic asthma. Clin Exp Immunol 1999;118:9-15. 
40 Zhou D, Chen G, Kim JT, Lee LY, Kang BC: A dose-response relationship between exposure to cockroach allergens and induction of sensitization in experimental asthma in Hartley guinea pigs. J Allergy Clin Immunol 1998;101:653-659.

-41 Gaultier C, Harf A, Lorino AM, Atlan G: Lung mechanics in growing guinea pigs. Respir Physiol 1984;56:217-228.

-42 Bates RFM, Shen X, Ramchandani R, Tepper RS, Bates JHT: Comparative respiratory system mechanics in rodents. J Appl Physiol 2000;89:908-916.

43 Amdur MO, Mead J: Mechanics of respiration in unanesthetized guinea pigs. Am J Physiol 1958;192:364-368.
-44 Meyer KC, Rosenthal NS, Soergel P, Peterson $\mathrm{K}$ : Neutrophils and low-grade inflammation in the seemingly normal aging human lung. Mech Ageing Dev 1998;104:169-181.

45 Evans CM, Fryer AD, Jacoby DB, Gleich GJ, Costello RW: Pretreatment with antibody to eosinophil major basic protein prevents hyperresponsiveness by protecting neuronal M2 muscarinic receptors in antigen-challenged guinea pigs. J Clin Invest 1997;100: 2254-2262.
46 Regal JF, Fraser DG, Toth CA: Role of the complement system in antigen-induced bronchoconstriction and changes in blood pressure in the guinea pig. J Pharmacol Exp Ther 1993;267:979-988.

47 Regal JF, Fraser DG: Systemic complement system depletion does not inhibit cellular accumulation in antihistamine pretreated allergic guinea pig lung. Int Arch Allergy Appl Immunol 1996;109:150-160.

48 Erjefalt JS, Korsgren M, Malm-Erjefalt M, Conroy DM, Williams TJ, Persson CGA: Acute allergic responses induce a prompt luminal entry of airway tissue eosinophils. Am J Respir Cell Mol Biol 2003;29:439-448. 